\title{
Experimental manipulation of photoperiod and temperature does not influence nest size in Blue and Great tits
}

\author{
Marcel M. Lambrechts ${ }^{1 *}$ and Samuel P. Caro ${ }^{1,2}$ \\ ${ }^{1}$ Centre d'Ecologie Fonctionnelle \& Evolutive (CEFE), Centre National de la Recherche Scientifique (CNRS), University of Montpellier, \\ Montpellier, France \\ ${ }^{2}$ Department of Animal Ecology, Netherlands Institute of Ecology (NIOO-KNAW), Wageningen, The Netherlands \\ * Corresponding author: marcel.lambrechts@cefe.cnrs.fr
}

Submitted August 30, 2017; Accepted November 29, 2017; Published February 7, 2018

\begin{abstract}
To anticipate future breeding conditions in spatiotemporally dynamic environments, any proximate aspect of breeding is expected to be causally associated with environmental cues or constraints. Photoperiod, ambient temperature, and food are considered to be among the most important environmental determinants of breeding performance. However, the importance of these determinants in the expression of nest size has not previously been investigated experimentally in laboratory conditions. We report that captive Blue Tits (Cyanistes caeruleus) and Great Tits (Parus major) did not adjust the size of their cavity nest to experimental changes in photoperiod or ambient-temperature regimes. Results did not change when we controlled for first-egg date and clutch size. In addition, captive birds fed ad libitum did not build larger nests than free-ranging breeders in standardized nest boxes. Thus, we report no evidence that nest size per se is proximately influenced by commonly studied environmental factors like photoperiod, temperature, food abundance, or the level of investment in egg production-factors that can all pose energetic challenges to breeding birds. However, we do not exclude the possibility that, in natural conditions, energy- or resource-associated constraints might influence aspects of nest design other than nest size (e.g., rare nest components) or that constraints on nest building might only be revealed when birds need to build substantially larger nests (i.e. in larger cavities). Therefore, additional experimental work will be required to determine which are the proximate determinants of nest design in cavity breeders.
\end{abstract}

Keywords: Blue Tit, breeding, Cyanistes caeruleus, Great Tit, nest size, Parus major

La manipulación experimental del fotoperiodo y la temperatura no influencian el tamaño del nido en Cyanistes caeruleus y Parus major

\section{RESUMEN}

Para anticipar las condiciones reproductivas futuras en ambientes espacial y temporalmente dinámicos, se espera que cualquier aspecto que influencie de modo directo la reproducción este causalmente asociado con señales o restricciones ambientales. Se considera que el fotoperiodo, la temperatura ambiente y el alimento están entre los determinantes ambientales más importantes del desempeño reproductivo. Sin embargo, hasta la fecha, la importancia de estos determinantes en la expresión del tamaño del nido no ha sido investigada experimentalmente en condiciones de laboratorio. Nuestros hallazgos indican que los individuos cautivos de Cyanistes caeruleus y Parus major no ajustaron el tamaño de sus nidos en cavidades a los cambios experimentales en los regímenes del fotoperiodo o de la temperatura ambiente. Los resultados no cambiaron cuando controlamos por la fecha del primer huevo y el tamaño de la nidada. Adicionalmente, las aves cautivas alimentadas ad libitum no construyeron nidos más grandes que las aves libres que criaron en cajas nido estandarizadas. De este modo, no hallamos evidencia de que el tamaño del nido per se esté influenciado directamente por los factores ambientales comúnmente estudiados como el fotoperiodo, la temperatura, la abundancia de alimentos o el nivel de inversión en la producción del huevo; todos factores que pueden representar desafíos energéticos para las aves reproductivas. Sin embargo, no excluimos la posibilidad de que en condiciones naturales, las restricciones energéticas o asociadas a los recursos podrían afectar aspectos del diseño del nido distintos al tamaño del nido (e.g., componentes raros del nido), o que las restricciones en la construcción del nido podrían manifestarse solo cuando las aves necesiten construir nidos sustancialmente más grandes (i.e., en cavidades más grandes). Por ende, se necesita trabajo experimental adicional para determinar cuáles son los determinantes directos del diseño del nido en las aves que crían en cavidades.

Palabras clave: Cyanistes caeruleus, Parus major, reproducción, tamaño del nido 


\section{INTRODUCTION}

Reproduction is likely one of the most energy-demanding life-history stages. Adaptive decision-making allows breeders to anticipate changes in the abiotic environment and reproduce at the right moment or to forgo reproduction altogether when environmental conditions are suboptimal. Thus, breeders have evolved proximate responses to a series of environmental cues (photoperiod, climate, food) in order to regulate reproductive functions so that their progeny are reared in optimal breeding conditions. In addition, breeding is often proximately inhibited by factors reflecting energetic constraints, such as low food abundance, short days, low ambient temperatures, or increased stress (e.g., Baker 1938, Farner 1961, Murton and Westwood 1977, Wingfield et al. 1992, Lambrechts et al. 1997). Breeding performance, including performance that is associated with nest building, is therefore expected to be proximately adjusted to changes in the abiotic environment and thus to change with latitude, altitude, or climate.

Although avian nests function to provide a safe environment for parents, eggs, and nestlings, nests differ considerably in size and shape (e.g., Hansell 2000, Mainwaring et al. 2014, Deeming and Mainwaring 2015). Birds have been predicted to build larger, more insulated, nests at more northern latitudes, at higher altitudes, during colder years, or earlier in the season (Nager and van Noordwijk 1992, Hansell 2000, Britt and Deeming 2011, Crossman et al. 2011, Deeming et al. 2012, Mainwaring et al. 2012, 2014, Heenan et al. 2015, Lambrechts et al. 2016). Longer days provide more opportunities to find the resources needed to build larger nests and have been shown to increase nest-building rates (Hinde et al. 1974). However, if breeders are time constrained, they are also expected to build smaller nests when they breed later in spring, under longer photoperiods (e.g., to speed up the breeding cycle to prevent progeny from fledging too late; e.g., Moreno et al. 2008, Lambrechts et al. 2012). Similarly, if low ambient temperatures are expected to induce larger and more insulated nests, the patterns of temperature changes during the prebreeding season could also inform birds about the local conditions and influence nest size, as was shown for egg-laying dates in Great Tits (Schaper et al. 2012b). A rapid seasonal increase in ambient temperature might indicate an advanced breeding season and induce an acceleration of the breeding schedule, perhaps resulting in the construction of smaller, and thus lighter, nests. Nest size, like any other aspect of breeding, is thus expected to be causally associated with one or more photoperiodic and/or non-photoperiodic environmental factors. Several correlative studies have shown a negative or no significant relationship between temperature and nest size (e.g., Deeming et al. 2012, Mainwaring et al. 2014). A recent study, using a long-term dataset, found no relationship with temperature but a negative one with rainfall (Lambrechts et al. 2016). However, direct evidence that investment in nest size is causally adjusted to changes in environmental factors is lacking because of the logistical difficulties of (1) experimentally inducing non-domesticated outdoor breeders to build nests outside their normal breeding window or (2) exposing nest-builders to an experimental change in climate-associated factors in wild conditions (e.g., Lambrechts et al. 1997, 1999; but for a brief discussion of a few case studies, see Deeming and Mainwaring 2015).

Here, we present the results of laboratory experiments in which captive Blue Tits (Cyanistes caeruleus) and Great Tits (Parus major) were exposed to different photoperiod and temperature regimes. In a first set of experiments, captive Corsican Blue Tits (C. c. ogliastrae) were triggered to build nests during cold weather in seminatural outdoor conditions by adding several hours of artificial light to the natural photoperiod. In previous studies, we showed that exposure to such long artificial photoperiods triggered these birds to significantly advance their breeding season so that eggs were produced during the coldest period of the year (e.g., Lambrechts et al. 1996, 1997, Lambrechts and Perret 2000). In a second set of experiments, conducted in indoor climate-controlled chambers, handreared captive Blue Tits and Great Tits were exposed to experimental changes in photoperiod and ambient temperature during their prebreeding periods. If ambient temperature proximately causes breeders to adjust nest size, independently from other abiotic or biotic factors, we expected that the birds would build larger nests under cold than under warm temperatures. If the absolute length of the photoperiod per se proximately causes breeders to adjust nest size, independent from non-photoperiodic factors, we expected that birds would build larger nests during longer photoperiods, since longer photoperiods provide more opportunities to find the resources needed to build larger nests. If, rather, the rate of change in the length of the photoperiod or in ambient temperature proximately causes breeders to adjust nest size, independent from other factors, we expected that birds would build more rapidly smaller nests when photoperiod or temperature increases rapidly (e.g., Moreno et al. 2008, Lambrechts et al. 2012). Apart from testing experimentally the roles of photoperiod and temperature, we also controlled for the influence of 2 other potential determinants of nest size, namely clutch size and laying date. Several studies have indeed explored and reported relationships between nest size, laying date, and/or clutch size (e.g., Moreno et al. 2008, Lambrechts et al. 2012, 2016, 2017, Møller et al. 2014). For example, early breeders or birds breeding in colder conditions could have the option to build larger, more insulated, nests and/or to lay larger clutches, thereby decreasing heat loss. But larger clutches in larger nests might also suffer from decreased 
incubation efficiency due to limitations of the brood patch and decreased temperature exchange between the brood patch and the individual eggs. Therefore, some plasticity in clutch size might interact and/or be related to some plasticity in nest size, depending, among other factors, on ambient temperatures. We thus also considered first-egg date and clutch size in our analyses. In our study, we focused on the proxies of nest size (nest volume, nest mass) that were investigated in all correlative field studies of cavity nests throughout Europe (e.g., Deeming et al. 2012, Deeming and Mainwaring 2015, Bueno-Enciso et al. 2016, Lambrechts et al. 2016).

\section{METHODS}

\section{Seminatural Outdoor Conditions: Blue Tits}

All Blue Tits that were used in the present experiment were trapped as adults in the wild, near the different study plots of the long-term studies in Corsica, except for 3 pairs that were hatched in captivity (Lambrechts et al. 1996, 1997, Lambrechts and Perret 2000, Blondel et al. 2006). Because we had found that the birds' population of origin did not statistically influence the size of the nests measured in the present study (data not shown), we did not further consider bird origin in our analyses. Pairs were formed at random, and we assigned them randomly to the different large outdoor aviaries (approximately $3 \times 3 \times 3 \mathrm{~m}$ ) at the Redon Campus (CNRS) in Montpellier, in mainland southern France. Each aviary contained 1 Blue Tit pair, 1 or 2 oak trees (mostly Quercus ilex), 2 nest boxes of the same type (see below), and food and water provided ad libitum. The ground of all aviaries was covered with soil and natural substrate including herbs. In addition, plenty of moss and lining material (hair, feathers, or wool) was provided so that the birds could fill up the nest chambers. Birds from adjacent aviaries could hear and see each other, and interactions with wild birds were possible.

Nest-size measures were taken in the aviaries from 1997 to 2005, following protocols described by Lambrechts et al. (2016). Birds nested in cylindrical, wood-and-concrete Schwegler B1 boxes (Schorndorf, Germany) or in concrete boxes, all of which had approximately the same nestchamber size (floor area $\sim 113 \mathrm{~cm}^{2}$, distance between entrance and bottom about 13-14 cm). Boxes were visited once a week to check the progress of each breeding attempt. The initiation and progress of nest building, and the laying dates of the first eggs of the first clutches, expressed in Julian dates (January $1=1$, February $1=32$ ), were recorded at each visit. After removing the front door of the box (cf. Lambrechts et al. 2012, 2016), we quantified nest building by measuring the vertical height of the external nest wall at $\pm 0.5 \mathrm{~cm}$ (measured from the bottom of the nest box to the top of the nest rim on the frontal part of the nest), also called "nest depth" (Hansell 2000), "nest height" (Lambrechts et al. 2012), or "nest thickness" (Hurtrez-Boussès et al. 1999). Thus, nest volume as a proxy of nest size was estimated by multiplying nest height with the inner surface of the standardized box floor (cf. Hurtrez-Boussès et al. 1999, Lambrechts et al. 2012, 2016).

During the study period, we exposed Blue Tits to at least 1 of 3 different photoperiod treatments (called A, C, and E hereafter; see Figure 1A), using the same outdoor aviaries and artificial food for each treatment, but with each of the treatments starting at a different time of year. Treatment A (egg-laying responses to this treatment have been published before; Lambrechts et al. 1996, 1997, Lambrechts and Perret 2000) consisted of natural daylight throughout the year and was used as a control treatment (similar photoperiodic conditions as the wild birds in Montpellier and Corsica). In treatments $\mathrm{C}$ and $\mathrm{E}$, Blue Tit pairs were presented with artificial photoperiods in which natural winter day lengths were elongated using artificial lights (one lamp of $500 \mathrm{~W}$ at $4 \mathrm{~m}$ above ground and 4 TL-tubes of $36 \mathrm{~W}$ at $3 \mathrm{~m}$ above ground in each aviary), which were switched on every night at midnight and were turned off at 10:00 AM, when natural light was present. Treatment C (for which egg-laying responses have also been published before; Lambrechts et al. 1996, 1997, Lambrechts and Perret 2000) consisted of a photoperiod that was readily increased to $17 \mathrm{hr}$ light:7 hr dark in mid-December 1998 and continued to increase as natural photoperiod increased (see Figure 1). Treatment E, for which egg-laying data have never been published, was identical to treatment $\mathrm{C}$, except that photoperiod was only artificially increased from mid-February onward (see Figure 1). This treatment was repeated from 2001 to 2003 .

To analyze the data, we first tested the effects of photoperiod treatment-(A) natural day length vs. (C) artificial long day from mid-December vs. (E) artificial long day from mid-February-on first-egg dates, clutch size, and nest size using linear mixed models (function lmer, package lme4 in R 3.4.1; R Core Team 2007). $P$ values were obtained with the package lmerTest 2.0-33 (Kuznetsova et al. 2016).

We also examined whether rainfall and temperature conditions at the time of nest building differed between the different photoperiod treatments in outdoor conditions, in order to test whether the birds that were exposed to the different photoperiod treatments also experienced different (uncontrolled) weather conditions.

Subsequently, instead of testing the effect of treatment on each separate variable, we introduced the effects of treatment, first-egg date, and clutch size into a single analysis of the nest-size data, using a linear mixed model. In a similar analysis, we kept the variables described above but replaced treatment with the meteorological data (temperature and rainfall) of the week preceding nest measurements. 

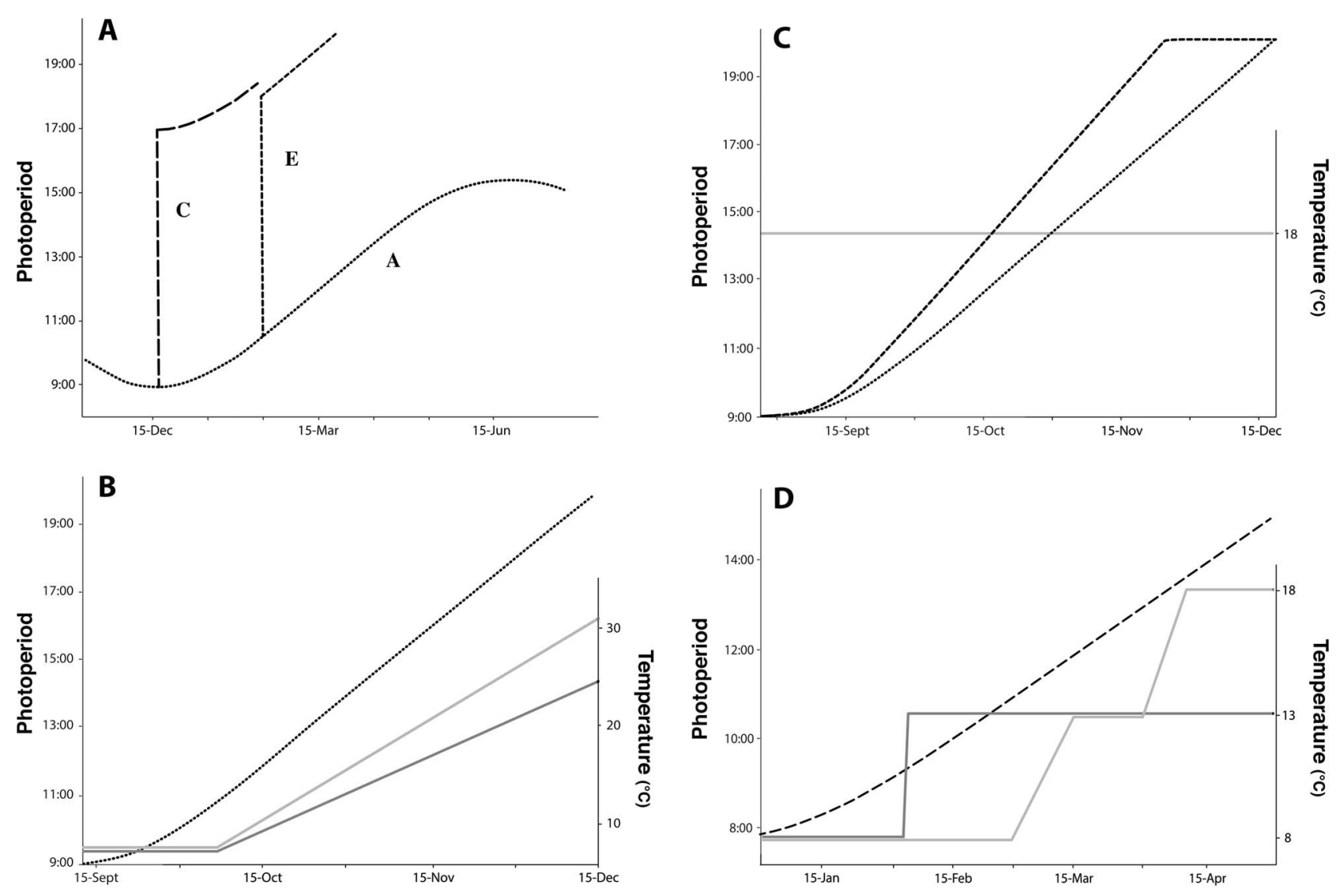

FIGURE 1. Experimental manipulations of photoperiod and ambient temperature in (A) outdoor aviaries and (B-D) climatecontrolled chambers. Experiments were conducted with $(\mathbf{A}-\mathbf{C})$ Blue Tits and (D) Great Tits. Dashed lines reflect experimental changes in photoperiod, and solid lines reflect experimental changes in ambient temperature.

Finally, we also compared the nest-size data from the captive birds with those from the wild ones, which were monitored following the same methods, during the same study years, and in the same box type in Corsica as in captivity. For this analysis, we pooled nest-size data from the different treatments in captivity ( $n=33$ nests) and ran a linear mixed model to compare nest sizes in captivity and in the wild.

Meteorological data from the Redon Campus were available and used to calculate the average ambient temperature and the additive amount of rain for each nest during the 7 days preceding the nest-size measures (Table 1). The meteorological station was situated at $\sim 50 \mathrm{~m}$ from the closest aviaries. Temperatures measured this way reflected temperatures inside the nest chambers (M. M. Lambrechts personal observation). Ambient and surface temperatures had indeed been measured inside and outside of 5 different kinds of nest boxes placed side by side, including wooden and Schwegler B1 boxes (with small and large entrance holes), using 2 different thermometers (TFH620, Ebro Electronic, Ingolstadt, Germany; and Powertec Energy infrared thermometer,
Kaleas, Denzlingen, Germany). Temperatures were measured both indoors and outdoors, with or without a nest inside the cavity, and at various times of the year and of the day. In all cases, temperatures inside and outside of the nest box were highly correlated $(P<0.0001$, data not shown), and the box's material composition, the size of the hole, and the presence-absence of a nest never affected the temperatures measured (all $P \geq 0.4$, data not shown).

\section{Controlled-climate Chambers: Blue Tits}

The hand-reared Blue Tits used for the 2 indoor experiments described here were hatched in the wild in 2010 and 2011. Nestlings 7-12 days posthatch were taken from the nest in different long-term study sites in Corsica. As with Great Tits, population of origin did not influence the size of the nests (data not shown) and will therefore not be considered further. After collection, chicks were transferred to the Netherlands (Netherlands Institute of Ecology, NIOO-KNAW, Wageningen) and hand reared following basic protocols (e.g., Drent et al. 2003, Reparaz et al. 2014). Once they were adults, birds were settled in opposite-sex pairs in 36 climate-controlled chambers $(2 \times$ 
TABLE 1. Mean ( \pm SD, with range below and sample size in parentheses) for first-egg date, clutch size, external ambient temperature during nest construction, additive amount of rainfall during nest construction, and nest volume as a proxy of nest size in captive Blue Tits exposed to 3 photoperiod treatments in outdoor aviaries in southern France. Also shown is the statistical significance of the effects of the photoperiod treatments on laying dates, clutch size, temperature, rainfall, and nest size.

\begin{tabular}{|c|c|c|c|c|c|}
\hline Measure & $\begin{array}{l}\text { Treatment A: } \\
\text { Natural day }\end{array}$ & $\begin{array}{c}\text { Treatment C: } \\
\text { Long day from mid-December } \\
(>17 \text { hr light:7 hr dark })\end{array}$ & $\begin{array}{c}\text { Treatment E: } \\
\text { Long day from mid-February } \\
(>17 \text { hr light:7 hr dark })\end{array}$ & $F$ & $P$ \\
\hline First-egg date (Julian date) & $\begin{array}{c}143 \pm 11(12) \\
119-157\end{array}$ & $\begin{array}{c}23 \pm 5(9) \\
16-31\end{array}$ & $\begin{array}{c}93 \pm 11(11) \\
80-116\end{array}$ & 405.75 & $<0.001 * * *$ \\
\hline Clutch size $(n)$ & $\begin{array}{c}5.3 \pm 1.6(12) \\
2-8\end{array}$ & $\begin{array}{c}7.6 \pm 1.4(9) \\
5-10\end{array}$ & $\begin{array}{c}7.6 \pm 2.5(11) \\
4-12\end{array}$ & 5.01 & $0.016^{*}$ \\
\hline Average temperature $\left({ }^{\circ} \mathrm{C}\right)$ & $\begin{array}{c}17.5 \pm 1.5(13) \\
13.7-19.8\end{array}$ & $\begin{array}{c}7.7 \pm 1.5(9) \\
5.8-10.1\end{array}$ & $\begin{array}{c}12.0 \pm 1.2(11) \\
10.6-14.5\end{array}$ & 133.74 & $<0.001 * * *$ \\
\hline Rain (mm) & $\begin{array}{c}24.6 \pm 28.0(13) \\
0-91.5\end{array}$ & $\begin{array}{c}18.0 \pm 8.2(9) \\
11-27\end{array}$ & $\begin{array}{c}6.8 \pm 15.8(11) \\
0-54\end{array}$ & 1.89 & 0.196 \\
\hline Nest size $\left(\mathrm{cm}^{3}\right)$ & $\begin{array}{c}599 \pm 277(13) \\
113-960\end{array}$ & $\begin{array}{c}514 \pm 294(9) \\
226-1130\end{array}$ & $\begin{array}{c}693 \pm 312(11) \\
339-1356\end{array}$ & 1.05 & 0.368 \\
\hline
\end{tabular}

$2 \times 2.25 \mathrm{~m}$; chamber walls made of white sandwich panels; one pair of birds per aviary; see also Visser et al. 2009, Schaper et al. 2012a, 2012b) under artificial light. Photoperiod was adjusted every day, and the main sources of light were 3 high-frequency, $36 \mathrm{~W}$ TL-tubes, which had different spectra in order to approach a natural range of wavelengths; 5 min before the TLs were switched on and 5 min after they were turned off, an $8 \mathrm{~W}$ light bulb mimicked dawn and dusk. Temperature was controlled $\pm 0.1^{\circ} \mathrm{C}$ by either heating or cooling the air that was circulated in the aviary. Photoperiod and temperature were centrally controlled by a computer, and each aviary could be controlled independently from the others. Inside each aviary, birds were provided several wooden perches, one artificial pine tree, several containers for food and water (both provided ad libitum), and 2 types of nest boxes (see below). All 36 aviaries were strictly identical.

The experiments were conducted in September in both 2013 and 2014. Each experiment ran for 3 mo. Prior to each experiment, the birds had been exposed to a short photoperiod (9 hr light:15 hr dark, i.e. the minimal photoperiod in Corsica) for $7 \mathrm{wk}$, to reset their photosensitivity (e.g., Dawson et al. 2001). Then, from September on, all the birds were exposed to a progressively increasing photoperiod. The photoperiod profile had the same shape as the natural spring increase in photoperiod, but it was increased faster in order to stimulate autumn breeding in captivity (see below).

In 2013, birds were all exposed to the same photoperiod but were allocated to 1 of 2 different temperature treatments, reflecting colder or warmer Mediterranean weather conditions. Photoperiod increased by $\leq 8 \mathrm{~min}$ day $^{-1}$ in both treatments. Temperature increased linearly but at different rates in each treatment (Figure 1B). The initial ambient temperature in which the pairs were housed, the date of initiation of the temperature increases, and the rates of increase were calculated on the basis of temperature data recorded in the field in Corsica. We used the average temperature recorded by iButtons in 3 different nest boxes over 3 consecutive years (20052007) at the 2 main study sites of Corsica from which the birds came. We selected temperature data recorded between March 1 and May 24, a time when temperatures are increasing almost linearly. During 86 consecutive days beginning March 1, the average ( \pm SD) ambient temperatures inside the nest boxes of the 2 sites were $12.7 \pm$ $3.8^{\circ} \mathrm{C}$ and $14.9 \pm 4.5^{\circ} \mathrm{C}$, respectively. We therefore presented the captive birds with a colder treatment (18 pairs) that was, on average, $\sim 2{ }^{\circ} \mathrm{C}$ lower than the warmer treatment (18 pairs) (Figure 1B). To keep a natural relationship between the increases in photoperiod and ambient temperature, we doubled the slope of the temperature increase in the climate chambers, as we did for photoperiod (i.e. twice as fast as in the wild). Temperature started increasing when the photoperiod reached $11 \mathrm{hr}$ light:13 hr dark, which would correspond approximately to March 1 in the wild.

In 2014, all birds were exposed to the same temperature but were allocated to 1 of 2 different photoperiods that increased linearly but at different rates in each treatment (Figure 1C). Photoperiod increased by $7 \mathrm{~min} \mathrm{day}^{-1}$ (17 pairs) or 9 min day $^{-1}$ (19 pairs). Birds were kept at a constant temperature regime of $18^{\circ} \mathrm{C}$ (i.e. above the average ambient temperature to which outdoor nest builders are exposed during first breeding attempts; Lambrechts et al. 2016).

Birds could nest in 2 wooden box types that differed slightly in bottom floor $\left(\sim 108 \mathrm{~cm}^{2}\right.$ vs. $\left.\sim 118 \mathrm{~cm}^{2}\right)$. Both box types were present in each aviary. The vast majority of birds (71\%) built their nests in the larger boxes, and, because few data were collected in the smaller of the 2 boxes, we did not consider box type in the statistical 
analyses presented below. Including box type in preliminary analyses showed that nests tend to be larger in the larger boxes, but it did not change the outcome of the other variables (data not shown). Overall, those 2 types of wooden boxes had a similar floor area as the Schweglertype boxes used in Mediterranean France, but they were deeper under the entrance hole $(\sim 16.2 \mathrm{~cm}$ vs. $\sim 17 \mathrm{~cm}$, respectively) than the Schwegler boxes (approximately 13$14 \mathrm{~cm}$ ). Moss and lining material (hair and wool fragments) were provided so that the birds could fill up the nest chambers.

The vertical height of the external nest wall used as a proxy of nest size was measured when the birds stopped egg laying (eggs were incubated for $\sim 5$ days), following the same procedures as above (see also Lambrechts et al. 2016). This nest measure was multiplied by the bottom floor area of the occupied box (108 or $\left.118 \mathrm{~cm}^{2}\right)$ to obtain the nest volume for each breeding attempt. Dry mass of these nests was also taken. In a few nests, we observed large discrepancies between the calculated nest volume (based on the height of the external nest wall) and the measured dry mass, for unknown reasons. These nests were not excluded from the dataset.

To analyze the data from the Blue Tits in climate chambers, we analyzed each experiment (and thus each environmental variable: temperature and photoperiod) separately, using linear models in R. Nest volume and dry mass were used as response variables; temperature or photoperiod, clutch size, and laying date were used as explanatory variables.

\section{Controlled-climate Chambers: Great Tits}

The hand-reared Great Tits used for the 2 yr experiment described here were hatched in 2010 and 2012 and originated from a long-studied Dutch population of Great Tits monitored at the NIOO (Wageningen). Chicks were hand reared following the same procedures as those described above for the Blue Tits (e.g., Drent et al. 2003). As with the Blue Tits, once the Great Tits became adults, they were settled in opposite-sex pairs in the same 36 climate-controlled aviaries $(2 \times 2 \times 2.25 \mathrm{~m}$, one pair of birds per aviary, same nest boxes as for the Blue Tit experiment above), in which temperature and photoperiod could be precisely controlled and monitored (see above).

The experiment was conducted in spring 2013 and was repeated in spring 2014. The experiment ran for $6 \mathrm{mo}$ in each year. Pairs of Great Tits were exposed to a photoperiod that mimicked the natural increase of day length in spring (same rate of increase as in the wild) and to 1 of 2 artificial temperature treatments (Figure 1D; 18 pairs treatment ${ }^{-1}$ ). In each year, experimental changes in ambient temperature were made from February 1 on. Temperature profiles were similar to those used in Schaper et al. (2012b), where the treatments induced significant differences in several Great Tit reproductive traits, including laying dates. Great Tits can thus perceive these temperature profiles as distinct reproductive cues, and we hypothesized that they would also influence nest size. Females were exposed to one temperature treatment in one year and to the other temperature treatment in the following year, randomizing the order of presentation of the 2 treatments across pairs of birds. That way, birds were exposed to both temperature treatments across years and acted as their own control.

To analyze the data from the Great Tits in the climate chambers, we examined the effects of the temperature regime, laying date, clutch size, and year on the nest mass of first breeding attempts using a mixed model (function lmer, package lme4 in R). $P$ values were obtained with the package lmerTest. Female identity was added as a random intercept to account for the fact that the same birds were used in both treatments (years).

\section{RESULTS}

\section{Seminatural Outdoor Conditions: Blue Tits}

In outdoor aviaries, exposing Blue Tits to artificially long days early in the year (treatment $\mathrm{C}$ and E; Figure 1A) triggered those birds to start laying several months before birds exposed to natural photoperiod (treatment A; see averages and $P$ values in Table 1). Clutch sizes also differed between treatments, with birds that bred early laying larger clutches than those that nested later in the season (Table 1). Average ambient temperatures measured during nest construction were much lower for the nests built early in the year than for those built later in the season (Table 1), but experienced rainfall did not significantly differ among treatments (Table 1). Despite the fact that birds bred at very different times, under very different temperatures, and laid clutches of different sizes, nest size did not differ statistically between the 3 treatments (Table 1). Thus, birds breeding in cold temperatures and rapidly changing photoperiods did not adjust the size of their nests accordingly.

Analyzing the effects of photoperiod treatment, first-egg date, and clutch size on nest-size data did not yield any significant results (all $P>0.2$ ). Similarly, replacing treatments by the weather experienced during the study did not yield different results (all $P>0.2$ ). Thus, nest volumes were influenced neither by the experimental photoperiod treatments nor by the additional variables that were tested.

Comparing overall nest sizes measured in captivity, where birds were fed ad libitum (nest volume in aviaries: $608 \pm 293 \mathrm{~cm}^{3}$, range: $113-1,356 \mathrm{~cm}^{3}$, data from the 3 treatments combined, $n=33$ nests) with those monitored in the same study years and the same box type in natural conditions (nest volume in the wild: $662 \pm 215 \mathrm{~cm}^{3}$, range: 
TABLE 2. Mean ( $\pm S D$, with range below) volume and dry mass of nests of Blue Tit and Great Tit pairs exposed to different temperature and photoperiod treatments in climate-controlled chambers (for details, see text and Figure 1). Nests were measured after the females stopped egg laying.

\begin{tabular}{|c|c|c|c|c|c|c|}
\hline \multirow[b]{3}{*}{ Measure } & \multicolumn{4}{|c|}{ Blue Tits } & \multirow{2}{*}{\multicolumn{2}{|c|}{$\frac{\text { Great Tits }}{\text { Temperature }(n=39)}$}} \\
\hline & \multicolumn{2}{|c|}{ Temperature $(n=15)$} & \multicolumn{2}{|c|}{ Photoperiod $(n=19)$} & & \\
\hline & Slow increase & Rapid increase & Slow increase & Rapid increase & One increase & Two increases \\
\hline Nest volume $\left(\mathrm{cm}^{3}\right)$ & $\begin{array}{c}980 \pm 323 \\
589-1,354\end{array}$ & $\begin{array}{c}1,019 \pm 240 \\
703-1,331\end{array}$ & $\begin{array}{c}861 \pm 226 \\
486-1,178\end{array}$ & $\begin{array}{c}880 \pm 169 \\
540-1,119\end{array}$ & - & - \\
\hline Nest mass (g) & $\begin{array}{c}17.8 \pm 6.4 \\
9.4-27.0\end{array}$ & $\begin{array}{c}19.8 \pm 4.2 \\
13.7-24.0\end{array}$ & $\begin{array}{c}19.5 \pm 5.5 \\
10.6-26.7\end{array}$ & $\begin{array}{c}18.6 \pm 4.5 \\
11.8-23.7\end{array}$ & $\begin{array}{c}20.8 \pm 7.3 \\
9.6-38.1\end{array}$ & $\begin{array}{c}19.9 \pm 5.9 \\
8.8-32.1\end{array}$ \\
\hline
\end{tabular}

$226-1,356 \mathrm{~cm}^{3}, n=592$ nests from Corsica) did not reveal any statistical difference $(F=1.73, P=0.13)$.

\section{Controlled-climate Chambers: Blue Tits}

Exposing Blue Tits to different temperature regimes in climate-controlled chambers did not influence the volume ( $F=0.12, P=0.733)$ or the mass $(F=0.28, P=0.606)$ of the nests built (Table 2). Clutch size and laying date did not further explain variation in nest volume and mass (all $P>$ $0.25)$.

Similarly, exposing Blue Tits to different photoperiods in the same climate chambers did not result in different nest volume $(F=0.04, P=0.844)$ or mass $(F=0.19, P=0.666)$. In this experiment, laying date had no effect on nest properties $(F=0.89, P=0.362)$, but nests tended to be lighter when clutches were larger $(F=3.33, P=0.088)$ (Table 2).

\section{Controlled-climate Chambers: Great Tits}

Exposing Great Tits to different temperature regimes in climate-controlled chambers did not influence the mass ( $F$ $=0.49, P=0.495, n=39$ ) of the nests built. Average nest mass was similar in both treatments (Table 2). Clutch size, laying date, and year did not further explain variation in nest mass (clutch size: $F=0.35, P=0.557$; laying date: $F=$ $0.91, P=0.349$; year: $F=0.01, P=0.908)$.

\section{DISCUSSION}

In 3 multiyear experiments, we found that nest size was not significantly associated with experimental changes in photoperiod and/or ambient temperature regimes in Blue and Great tits. Birds bred in a wide range of abiotic conditions, including the coldest outdoor conditions of the year, which represented unusually cold breeding weather for these Mediterranean birds. Even in these extreme conditions, birds did not build larger nests than those exposed to more classical, warmer, temperatures later in the year. When we housed Blue and Great tits in climate-controlled chambers, where we could directly manipulate the temperature to which the birds were exposed, we obtained similar results: Birds exposed to lower ambient temperatures and/or lower rates of temperature increase did not build larger nests than those exposed to warmer and more rapidly increasing temperatures. Like temperature, photoperiod did not seem to influence the size of the nests that tits built, both in outdoor aviaries and climate-controlled chambers.

Although nest building has been described as an energydemanding activity (e.g., Tomás et al. 2006, Mainwaring and Hartley 2013, Mainwaring et al. 2014), it seems unlikely that the relatively weak investment in nest building observed here (particularly for birds that bred during winter) could be explained by an energy-based constraint. First, the birds exposed to the unusually long photoperiods obviously had more time to build a nest than those exposed to natural photoperiods. Second, wild tits build larger or heavier nests when larger nest chambers are provided (e.g., Slagsvold and Amundsen 1992, Mazgajski and Rykowska 2008, Møller et al. 2014, Lambrechts et al. 2017). Because we used boxes with relatively small chambers in our aviaries, the nests were substantially smaller than the nest sizes that Blue Tits are able to construct when larger nest chambers are provided (Møller et al. 2014). Third, we found that the nests of the captive outdoor pairs were not larger than those of the pairs that used the same box type in the same study years in the wild, even though birds in aviaries did not have to forage, defend a territory, or care for predators, and they received food ad libitum. Finally, the absence of a significant energy-based constraint on the reproductive investment during long-day treatments is also supported by the fact that the birds exposed to artificially long days began laying only 3-5 wk after the start of the long-day treatment, which is a shorter period than the 7-8 wk period between the start of rapid gonadal development and the start of first clutches reported in wild tits (Lebeurier and Rapine 1944, Lambrechts et al. 1997, Caro et al. 2006). This does not exclude the possibility that in natural conditions, energyassociated constraints might influence other aspects of nest design than size, such as specific nest components 
that are difficult to find in the territory (e.g., Mainwaring and Hartley 2013, and references therein).

The populations from the Mediterranean region are expected to express vast plasticity in their breeding responses to a change in ambient temperature (Silverin et al. 2008, Bourgault et al. 2010). However, the impact of the non-photoperiodic factors on reproductive investment might become insignificant after exposure to very long photoperiods, for instance when the proximate response mechanism to ambient temperature would change with the length of the photoperiod (Lambrechts and Perret 2000). From an adaptive point of view, a long photoperiod is an indicator of an advanced breeding season and therefore might proximately accelerate the breeding cycle, causing breeders to build, more rapidly, smaller nests (e.g., to prevent offspring from fledging too late; Lambrechts and Perret 2000, Lambrechts et al. 2012). We therefore expected smaller nests, on average, in the captive outdoor pairs that were exposed to the 2 long-photoperiod treatments simulating an advanced season (treatments $\mathrm{C}$ and E) compared to the outdoor controls exposed to natural photoperiods (treatment A), which was not the case. In addition, we observed that the hand-reared pairs from the climate-controlled chambers that faced the same ambient temperature but were exposed to different rates of increase in photoperiod built nests of similar size and mass. Photoperiodic factors are therefore apparently not causally involved in the expression of nest size. However, additional experimental work, also based on larger samples, will be required to determine the exact proximate relationships between aspects of nest design and day length.

The results of Deeming et al's (2012) correlative 1 yr field study suggest that ambient temperature can have a direct effect on nest-building behavior, with larger nests built in colder temperatures. Early breeders, also assumed to be in better physical condition than late breeders, should be able to build bigger nests (e.g., Tomás et al. 2006, Mainwaring and Hartley 2013) but also have a higher probability of being exposed to colder weather during the shorter days early in the season. However, Lambrechts et al. (2016) did not find significant associations between nest size and the ambient temperature expressed around the onset of egg laying in a multiplot study in free-ranging Mediterranean tits that lasted $18 \mathrm{yr}$ and that took several biotic and abiotic factors into account. This absence of a significant relationship between nest size per se and ambient temperature was also supported by the results of our experiments that quantified nest size in the climatecontrolled chambers that simulated various temperature profiles. In addition, nest size remained disassociated from ambient temperature in unusual weather conditions as shown with the birds used in our outdoor aviary experiments. Thus, our results support the absence of any direct causal effect of ambient temperature on nest size per se. It does not exclude that nest components other than nest size might be adjusted to changes in ambient temperature, as supported by observations of correlative studies in free-ranging conditions (e.g., lining material; Deeming et al. 2012, Mainwaring et al. 2012, Deeming and Mainwaring 2015). Here again, additional experimental work will be required to examine the underlying mechanisms of relationships between nest design (e.g., the depth of the cup, the thickness of the nest linings, the materials selected for the nest itself and for the lining, and the density of the nest) and ambient temperature or other aspects of weather (see also, e.g., Deeming and Mainwaring 2015, Lambrechts et al. 2016). Future studies could also look at the consequences for nest design of experimental changes in (1) microclimate inside the nest chamber or (2) insular properties of nesting cavities (e.g., Nager and van Noordwijk 1992).

\section{Conclusions}

We did not find experimental support that nest size (i.e. volume and weight) is causally associated with changes in photoperiod and ambient temperature in experimental laboratory settings. In addition, in our experiments, nest size did not seem to result from an energetically constrained process because, among other factors, captive birds that were fed ad libitum built nests of similar sizes to those of their wild counterparts. Obviously, additional experimental work that also focuses on other aspects of nest design than nest size per se will be required to determine the relative importance of the photoperiodic and non-photoperiodic proximate determinants in the expression of nest-building performance.

\section{ACKNOWLEDGMENTS}

We thank all the people who helped maintain the birds and the experimental setups in Montpellier (CEFE) and Wageningen (NIOO), in particular M. Aaldering, F. Kropman, B. van Lith, and K. van Oers, who took care of the birds at NIOO and helped with the experiments; and P. Perret, D. Degueldre, and C. Bernard, who helped with the aviary work at CEFE and provided the local temperature data. M. Mainwaring, C. Doutrelant, and two anonymous reviewers provided constructive comments on the manuscript.

Funding statement: Research was supported by CNRS and by several research grants, including an NWO-VENI and a WBI-World grant to S.P.C.

Ethics statement: The experimental settings were large outdoor aviaries (approximately $3 \times 3 \times 3 \mathrm{~m}$ ) or large indoor climate chambers $(2 \times 2 \times 2.25 \mathrm{~m})$ that allowed breeding following maintenance and monitoring procedures that were detailed in other publications (cf. Lambrechts et al. 1996, 1997, Lambrechts and Perret 2000, Visser et al. 2009, Schaper 
et al. 2012a, 2012b). During the multiyear study periods, Blue Tits were trapped and maintained under licenses 97/651/AUT and 99/365/AUT of the Ministère de l'environnement, France. The experiments run at NIOO were approved by the Animal Experimentation Committee of the Royal Dutch Academy of Sciences (DEC-KNAW; permit nos. CTE.09-04, NIOO12.09, and NIOO12.19). Fieldwork concerning the hand-reared birds was approved by the prefectural office of Corsica and the Regional Direction of Environment (DIREN) committee (permit nos. 2009-0379 and 3467).

Author contributions: Both authors equally shared their contributions in conceiving the study and writing the manuscript and have no competing interests.

Data deposits: Data are available from the authors upon request.

\section{LITERATURE CITED}

Baker, J. R. (1938). The evolution of breeding seasons. In Evolution: Essays on Aspects of Evolutionary Biology (G. R. De Beer, Editor). Oxford University Press, Oxford, UK. pp. 161177.

Blondel, J., D. W. Thomas, A. Charmantier, P. Perret, P. Bourgault, and M. M. Lambrechts (2006). A thirty-year study of phenotypic and genetic variation of Blue Tits in Mediterranean habitat mosaics. BioScience 56:661-673.

Bourgault, P., D. Thomas, P. Perret, and J. Blondel (2010). Spring vegetation phenology is a robust predictor of breeding date across broad landscapes: A multi-site approach using the Corsican Blue Tit (Cyanistes caeruleus). Oecologia 162:885892.

Britt, J., and D. C. Deeming (2011). First-egg date and air temperature affect nest construction in Blue Tits Cyanistes caeruleus, but not in Great Tits Parus major. Bird Study 58:7889.

Bueno-Enciso, J., E. S. Ferrer, R. Barrientos, and J. J. Sanz (2016). Effect of nestbox type on the breeding performance of two secondary hole-nesting passerines. Journal of Ornithology 157:759-772.

Caro, S. P., M. M. Lambrechts, O. Chastel, P. J. Sharp, D. W. Thomas, and J. Balthazart (2006). Simultaneous pituitarygonadal recrudescence in two Corsican populations of male Blue Tits with asynchronous breeding dates. Hormones and Behavior 50:347-360.

Crossman, C. A., V. G. Rohwer, and P. R. Martin (2011). Variation in the structure of bird nests between northern Manitoba and southeastern Ontario. PLOS One 6:e19086.

Dawson, A., V. M. King, G. E. Bentley, and G. F. Ball (2001). Photoperiodic control of seasonality in birds. Journal of Biological Rhythms 16:365-380.

Deeming, D. C., and M. C. Mainwaring (2015). Functional properties of nests. In Nests, Eggs, and Incubation: New Ideas about Avian Reproduction (D. C. Deeming and S. J. Reynolds, Editors). Oxford University Press, Oxford, UK. pp. 29-49.

Deeming, D. C., M. C. Mainwaring, I. R. Hartley, and S. J. Reynolds (2012). Local temperature and not latitude determines the design of Blue Tit and Great Tit nests. Avian Biology Research 5:203-208.
Drent, P. J., K. van Oers, and A. J. van Noordwijk (2003). Realized heritability of personalities in the Great Tit (Parus major). Proceedings of the Royal Society B 270:45-51.

Farner, D. S. (1961). Comparative physiology: Photoperiodicity. Annual Review of Physiology 23:71-96.

Hansell, M. (2000). Bird Nests and Construction Behaviour. Cambridge University Press, Cambridge, UK.

Heenan, C. B., B. A. Goodman, and C. R. White (2015). The influence of climate on avian nest construction across large geographic gradients. Global Ecology and Biogeography 24: 1203-1211.

Hinde, R. A., E. Steel, and B. K. Follett (1974). Effect of photoperiod on oestrogen-induced nest-building in ovariectomized or refractory female canaries (Serinus canarius). Journal of Reproduction and Fertility 40:383-399.

Hurtrez-Boussès, S., M. de Garine-Wichatitsky, P. Perret, J. Blondel, and F. Renaud (1999). Variations in prevalence and intensity of blow fly infestations in an insular Mediterranean population of Blue Tits. Canadian Journal of Zoology 77:337341.

Kuznetsova, A., P. B. Brockhoff, and R. H. B. Christensen (2016). ImerTest: Tests in Linear Mixed Effects Models. R package version 2.0-33. https://CRAN.R-project.org/package=ImerTest

Lambrechts, M. M., and P. Perret (2000). A long photoperiod overrides non-photoperiodic factors in Blue Tits' timing of reproduction. Proceedings of the Royal Society of London, Series B 267:585-588.

Lambrechts, M. M., C. Aimé, A. Midamegbe, M.-J. Galan, P. Perret, A. Grégoire, and C. Doutrelant (2012). Nest size and breeding success in first and replacement clutches: An experimental study in Blue Tits Cyanistes caeruleus. Journal of Ornithology 153:173-179.

Lambrechts, M. M., J. Blondel, C. Bernard, S. P. Caro, A. Charmantier, V. Demeyrier, C. Doutrelant, G. Dubuc-Messier, A. Fargevieille, C. de Franceschi, P. Giovannini, et al. (2016). Exploring biotic and abiotic determinants of nest size in Mediterranean Great Tits (Parus major) and Blue Tits (Cyanistes caeruleus). Ethology 122:492-501.

Lambrechts, M. M., J. Blondel, M. Maistre, and P. Perret (1997). A single response mechanism is responsible for evolutionary adaptive variation in a bird's laying date. Proceedings of the National Academy of Sciences USA 94:5153-5155.

Lambrechts, M. M., A. Charmantier, V. Demeyrier, A. Lucas, S. Perret, M. Abouladzé, M. Bonnet, C. Canonne, V. Faucon, S. Grosset, G. le Prado, et al. (2017). Nest design in a changing world: Great Tit Parus major nests from a Mediterranean city environment as a case study. Urban Ecosystems 20:11811190.

Lambrechts, M. M., P. Perret, and J. Blondel (1996). Adaptive differences in the timing of egg laying between different populations of birds result from variation in photoresponsiveness. Proceedings of the Royal Society of London, Series B 263:19-22.

Lambrechts, M. M., P. Perret, M. Maistre, and J. Blondel (1999). Do experiments with captive non-domesticated animals make sense without population field studies? A case study with Blue Tits' breeding time. Proceedings of the Royal of London, Series B 266:1311-1315.

Lebeurier, E., and J. Rapine (1944). La mésange bleue. Oiseau 14: 5-31. 
Mainwaring, M. C., and I. R. Hartley (2013). The energetic costs of nest building in birds. Avian Biology Research 6:12-17.

Mainwaring, M. C., I. R. Hartley, S. Bearhop, K. Brulez, C. R. du Feu, G. Murphy, K. E. Plummer, S. L. Webber, S. J. Reynolds, and D. C. Deeming (2012). Latitudinal variation in Blue Tit and Great Tit nest characteristics indicates environmental adjustment. Journal of Biogeography 39:1669-1677.

Mainwaring, M. C., I. R. Hartley, M. M. Lambrechts, and D. C. Deeming (2014). The design and function of birds' nests. Ecology and Evolution 20:3909-3928.

Mazgajski, T. D., and Z. Rykowska (2008). Dependence of nest mass on nest hole depth in the Great Tit Parus major. Acta Ornithologica 43:49-55.

Møller, A. P., F. Adriaensen, A. Artemyev, J. Bańbura, E. Barba, C. Biard, J. Blondel, Z. Bouslama, J.-C. Bouvier, J. Camprodon, F. Cecere, A. Charmantier, et al. (2014). Variation in nest size in relation to clutch size in birds. Ecology and Evolution 4:35833595.

Moreno, J., J. Martínez, C. Corral, E. Lobato, S. Merino, J. Morales, J. Martínez-de la Puente, and G. Tomás (2008). Nest construction rate and stress in female Pied Flycatchers Ficedula hypoleuca. Acta Ornithologica 43:57-64.

Murton, R. K., and N. J. Westwood (1977). Avian Breeding Cycles. Clarendon Press, Oxford, UK.

Nager, R. G., and A. J. van Noordwijk (1992). Energetic limitation in the egg-laying period of Great Tits. Proceedings of the Royal Society of London, Series B 249:259-263.

R Core Team (2017). R: A Language and Environment for Statistical Computing. R Foundation for Statistical Computing, Vienna, Austria. https://www.R-project.org/
Reparaz, L. B., K. van Oers, M. Naguib, C. Doutrelant, M. E. Visser, and S. P. Caro (2014). Mate preference of female Blue Tits varies with experimental photoperiod. PLOS One 9:e92527.

Schaper, S. V., A. Dawson, P. J. Sharp, S. P. Caro, and M. E. Visser (2012a). Individual variation in avian reproductive physiology does not reliably predict variation in laying date. General Comparative Endocrinology 179:53-62.

Schaper, S. V., A. Dawson, P. J. Sharp, P. Gienapp, S. P. Caro, and M. E. Visser (2012b). Increasing temperature, not mean temperature, is a cue for avian timing of reproduction. The American Naturalist 179:E55-E69.

Silverin, B., J. Wingfield, K.-A. Stokkan, R. Massa, A. Järvinen, N.-Å. Andersson, M. Lambrechts, A. Sorace, and D. Blomqvist (2008). Ambient temperature effects on photo induced gonadal cycles and hormonal secretion patterns in Great Tits from three different latitudes. Hormones and Behavior 54:60-68.

Slagsvold, T., and T. Amundsen (1992). Do Great Tits adjust hatching spread, egg size and offspring sex ratio to changes in clutch size? Journal of Animal Ecology 61:249-258.

Tomás, G., S. Merino, J. Moreno, J. J. Sanz, J. Morales, and S. García-Fraile (2006). Nest weight and female health in the Blue Tit (Cyanistes caeruleus). The Auk 123:1013-1021.

Visser, M. E., L. J. M. Holleman, and S. P. Caro (2009). Temperature has a causal effect on avian timing of reproduction. Proceedings of the Royal Society B 276:23232331.

Wingfield, J. C., T. P. Hahn, R. Levin, and P. Honey (1992). Environmental predictability and control of gonadal cycles in birds. Journal of Experimental Zoology 261:214-231. 